\title{
PROFESSORES NÃO HABILITADOS E OS PROGRAMAS ESPECIAIS DE FORMAÇÃO DE PROFESSORES: a tábua de salvação ou a descaracterização da profissão?
}

\author{
Non-qualified teachers and the special \\ development teachers programs: a life-saver or a \\ non-characterization of teaching
}

\begin{abstract}
Laurizete Ferragut Passos ${ }^{a}$, Neusa da Silva Cardoso de Oliveira ${ }^{b}$
a Professora do Programa de Estudos Pós-Graduados em Educação Matemática da PUC/SP, São Paulo, SP - Brasil, e-mail: laurizet@terra.com.br

${ }^{b}$ Mestre em Educação Matemática pelo Programa de Estudos Pós-Graduados em Educação Matemática da PUC/SP, São Paulo, SP - Brasil, e-mail: neusaoli@terra.com.br
\end{abstract}

\section{Resumo}

O presente trabalho busca contribuir para as discussões sobre as políticas de formação de professores e das diferentes modalidades de formação que vêm sendo implementadas no país a partir da década de 1990. Tomou-se para o estudo o Programa Especial de Formação de Professores e os dados referem-se à pesquisa desenvolvida num curso da área de matemática e funcionando na capital de um dos Estados mais desenvolvidos do país - a cidade de São Paulo. A sala de aula estudada compunha-se de alunos bacharéis de diferentes áreas, como arquitetos, administradores, engenheiros e parte deles já atuando como professores de matemática 
e que buscavam a certificação da Licenciatura Plena com carga horária pequena e reduzidos encontros semanais. Buscou-se, então, investigar esse espaço de formação docente a partir do olhar dos alunos que o cursaram tomando, para isso, uma análise de suas percepções e motivações para o ingresso e buscando verificar também o funcionamento do curso e analisar seu papel em relação à possível descaracterização da profissão docente.

Palavras-chave: Formação de professores; Cursos de licenciatura; Políticas públicas.

\begin{abstract}
The present study aims to contribute to the discussions about the policies that refer to teacher formation and the different formation modalities that have been and are being implemented in the country since the 1990's. The Special Program of Teacher Formation has been used for this study and the data refer to a research developed in a mathematics course and which took place in the capital of one of the most-highly developed states in the country - the city of São Paulo. The classroom studied was composed of graduated Bachelor students in varied areas, such as architects, administrators, engineers and part of them had already been working as mathematics teachers and were preparing for their teacher certification, having a small workload and a reduced number of weekly meetings. The decision was made to investigate this area of teacher formation through the eyes of the student taking the course and, through this, an analysis of his perceptions and motivations for entering, as well as, seeking to verify how the course functioned and analyze its role relative to the possible decharacterization of the teaching profession.
\end{abstract}

Keywords: Teacher formation; Teacher certification; Public polices.

O título desse artigo é decorrente da indignação das autoras frente a duas fontes de informação: a primeira refere-se aos dados sobre a falta de professores hoje no país em algumas áreas do conhecimento e, a outra, atrelada à primeira, volta-se para a expansão do Programas Especiais para Formação de Professores, hoje oferecidos por um grande número de instituições privadas no nosso país.

Rev. Diálogo Educ., Curitiba, v. 8, n. 23, p. 105-120, jan./abr. 2008 
A carência de 270 mil professores de matemática, química, física e biologia nas escolas do país foi destacada pelo próprio Ministério da Educação (MEC) e é apontada como conseqüência de 10 a 15 anos de verdadeiro descalabro na gestão do ensino público, do desmonte do Estado e do esvaziamento da Educação Pública. ${ }^{1}$ Nesse sentido, revela um problema estrutural e não exclusivamente emergencial (FREITAS, 2007), pois expressa como vem sendo historicamente retirada a responsabilidade do Estado na manutenção de uma educação pública de qualidade e de formação de seus professores.

Esses dados causam preocupação à medida que vêm sendo implementadas alternativas conjunturais para o enfrentamento do grave problema da falta de professores, dentre elas a complementação pedagógica em licenciaturas paralelas de 540 horas ou licenciaturas "rápidas" de 120 horas aos bacharéis de qualquer área, objeto desse nosso estudo. Fazem parte desse conjunto de iniciativas a criação do Programa Pró-licenciatura (2005) e o Programa da Universidade Aberta do Brasil (2006), todos ligados à educação a Distância que institucionalizam os programas de formação de professores à distância como política pública de formação (FREITAS, 2007).

A análise trazida pela autora e por nós compartilhada é a de que tais programas não "equacionarão a escassez na direção de uma política de valorização da formação de professores" e que, ao contrário, "aprofundarão o quadro de sua desprofissionalização pela flexibilização e aligeiramento da formação" (FREITAS, 2007, p. 1207).

Tais informações são provocativas e vêm confirmar a necessidade de estudos sobre o Programa Especial de Formação de Professores. A pesquisa analisada concentrou-se num curso dessa modalidade na área de matemática e funcionando na capital de um dos Estados mais desenvolvidos do país - a cidade de São Paulo. A sala de aula estudada compunha-se de alunos bacharéis de diferentes áreas, como arquitetos, administradores, engenheiros e parte deles já atuando como professores de matemática e que buscavam a certificação da Licenciatura Plena com carga horária pequena e reduzidos encontros semanais. Buscou-se, então, investigar esse espaço de formação docente a partir do olhar dos alunos que o cursaram tomando, para isso, uma análise de suas percepções e motivações para o ingresso e buscando verificar também o funcionamento do curso e analisar seu papel em relação à possível descaracterização da profissão docente.

1 Cf. matéria "MEC pode usar Ensino a Distância por falta de docentes". Disponível em www.mec.gov.br

Rev. Diálogo Educ., Curitiba, v. 8, n. 23, p. 105-120, jan./abr. 2008 


\section{A necessidade de professores habilitados no Brasil}

Qualquer análise que se faça sobre a questão da formação dos professores no Brasil na década de 90 não pode ser descolada das orientações do Banco Mundial já destacadas e analisadas por diversos autores. De qualquer modo, vale lembrar que o Banco Mundial, a partir da Conferência Mundial de Educação para Todos, realizada em Jontiem, Tailândia, em 1990, reforça seus investimentos no Ensino Fundamental.

Para isso, era preciso criar meios para que o país pudesse atender às novas demandas, criando mecanismos e opções para formar mais professores, num curto espaço de tempo e ao menor custo possível, ou seja, "uma formação mais curta e fora das universidades", segundo aponta Carnoy (1999 apud MAUÉS, 2003, p. 95), como sugestão do BM, deixando essa responsabilidade para outros setores, como o privado, por exemplo.

A fim de atender à demanda de "Educação para Todos", buscava-se evidenciar a necessidade de professores habilitados - licenciados - no Brasil, na década de 90. Os dados apresentados por Patinha (1999) sobre professor nãohabilitado da rede pública do Estado de São Paulo é revelador do número de professores lecionando sem habilitação nesse Estado e é apontado como um sinal da crise na educação.

A autora parte do conceito de crise na Educação ao constatar a tendência crescente de professores não-habilitados ${ }^{2}$ no período compreendido entre 1992 e 1996.

Em sua pesquisa, Patinha investigou o número de professores que atuavam na escola pública estadual e identificou suas áreas de formação e as disciplinas que vinham lecionando no Ensino Fundamental e Médio. Os dados corroboraram a idéia de que não é possível um trabalho de qualidade na rede pública de ensino quando são ainda admitidos professores sem habilitação requerida para exercer a profissão. A falta de professores habilitados, oriundos da Academia, permitiu o alto índice de professores não-habilitados, muitos dos quais estudantes de outras áreas ou profissionais formados em áreas não relacionadas com as disciplinas que ministravam e que buscavam a docência como alternativa enquanto não encontravam melhores cargos em suas profissões. Esses profissionais lecionavam com ALs (Autorizações para Lecionar) como comprova o estudo de Patinha.

Como o foco de nosso estudo é o PEFP (Programa Especial de Formação Pedagógica), torna-se relevante trazer dados que justifiquem a origem de sua existência, e sua normatização pela Resolução 02/1997 do MEC.

2 A autora atribui o termo aos professores não habilitados para o trabalho docente a partir da Licenciatura Plena, ou seja, são estudantes ou profissionais de outras áreas sem a graduação na área específica para a disciplina que lecionam.

Rev. Diálogo Educ., Curitiba, v. 8, n. 23, p. 105-120, jan./abr. 2008 
Os dados de Patinha apontam o número de professores não concursados da região metropolitana de São Paulo, em 1993 e 1994, apresentando a deficiência do sistema educacional do Estado. Em 1993, havia 149.827 professores lecionando nas classes do segundo segmento do Ensino Fundamental e no Ensino Médio e em 1994 o número cai para 147.302.

É possível perceber a necessidade de docentes na rede pública estadual e a baixa procura por profissionais habilitados, já que o concurso público realizado em 1994 garantiu apenas parte da necessidade de profissionais qualificados para o cargo.

No entanto, o estudo não culpabiliza os professores e indica que eles não são a causa, mas o reflexo da crise em que se encontra a educação.

Apresentamos, ainda, o número de ALs (autorizações para lecionar) emitidas pela SEE, no período de 1992 a 1996, identificando o alto índice de professores não-habilitados que lecionavam nos Ensinos Fundamental e Médio. Em 1992, 30.47\% possuíam tal licença e, em 1996, o número cai para 28,80\%.

Um estudo mais recente (ARANHA, 2007) sobre professores eventuais que atuam nas escolas públicas no interior de São Paulo revela que essa figura de substituto ou eventual vem atuando de maneira crescente nas escolas e ministrando qualquer disciplina em classes de $5^{a}$ a $8^{a}$ séries, sem possuir a habilitação necessária para substituir o professor ausente. A investigação aponta para a fragilização e desprofissionalização do trabalho docente e indica que as atividades do eventual, da forma como vem acontecendo, materializam a descaracterização do trabalho docente.

Os estudos acima, embora revelem a situação de precarização do trabalho do professor, mostram a necessidade de se pensar em alternativas para uma formação e habilitação de qualidade para esses professores.

No entanto, não se parte em nossa pesquisa do pressuposto de que para resolver o problema dos não-habilitados sejam implementados cursos de Licenciatura que tenham como principal meta certificar o maior número de professores, em curto espaço de tempo e sem condições adequadas para tal.

Desta maneira, adentramos no que aqui chamamos de "ciclo de necessidades". O aumento do número de alunos matriculados leva à necessidade do aumento do quadro docente. Como não há professores suficientes para atender a essa demanda, há a necessidade de formar professores rapidamente. Assim, surgem os cursos de curta duração. Porém, esses cursos podem não garantir uma formação com a qualidade de que necessitamos. Essa formação "rápida", associada à falta de experiência profissional desses novos professores, leva à menor qualificação na formação dos alunos dos Ensinos Fundamental e Médio. Como não temos professores, criamos maneiras de formar novos professores rapidamente e, assim, o ciclo se reinicia.

Rev. Diálogo Educ., Curitiba, v. 8, n. 23, p. 105-120, jan./abr. 2008 
A necessidade de professores habilitados gera a urgência de cursos de curta duração; e a necessidade de professores melhor qualificados gera a necessidade de qualificação.

Então surge a questão: Como é possível aumentar o quadro docente rapidamente e, ao mesmo tempo, melhorar a qualidade da formação docente e discente em nosso país?

Essas parecem ser questões contraditórias, pois temos necessidades diferentes: maior quantidade de professores e com garantia da qualidade de sua formação. A isso chamamos de "ciclo de necessidades".

No entanto, essa situação que causa tanta preocupação não é recente, pois o sistema de ensino desde a década de 1980, especialmente com a criação das licenciaturas curtas, revelava os crônicos problemas a serem enfrentados em relação à formação dos professores. Warde (1985, p. 79) já anunciava à época que aligeiradas e encurtadas, as licenciaturas passam a oferecer à escola de $1^{\circ}$ e $2^{\circ}$ graus pública professores cada vez menos preparados a enfrentar, pedagógica e socialmente, os problemas e as exigências cotidianas desses graus de ensino.

O estudo já clássico ocorrido na mesma década e denominado Novos Rumos da Licenciatura (CANDAU, 1989) trouxe análises posteriores em relação às questões desafiadoras sobre a formação dos professores. Conforme destacou Lüdke, os entrevistados da pesquisa (professores de Física, de História e Geografia e de Língua e Literatura Portuguesa) perceberam a formação de professores:

Como uma atividade que vem sendo exercida contra as forças dominantes na instituição, ou 'contra a maré [...] não é uma atividade valorizada, não recebe incentivos ou estímulos e, até, pode acarretar, para os que ela se dedicam, certa reputação um pouco inconveniente, à medida que os afasta, no julgamento de boa parte dos colegas, das atividades nobres ligadas usualmente à pesquisa. (LÜDKE, 1997, 141).

Outra pesquisadora que tem se debruçado em seus estudos sobre o ligeiramento dos cursos de Licenciatura é Dias-da-Silva. Partindo da idéia de que a profissionalização dos professores está diretamente ligada à trajetória dos cursos de Licenciatura, a autora também destaca o desprestígio da área da Educação nos embates pela hegemonia do campo e o conseqüente desprestígio dos cursos de licenciatura:

Assim, a criação dos cursos de licenciatura aparece muito mais como um ônus que os cientistas pagaram para consolidar seus projetos de formação dos bacharéis, o

Rev. Diálogo Educ., Curitiba, v. 8, n. 23, p. 105-120, jan./abr. 2008 
Professores não habilitados e os programas especiais de formação de professores

que possibilitou que, desde os anos oitenta, essa tarefa 'pouco nobre' fosse assumida pelas faculdades particulares. (DIAS DA SILVA, 2005, p. 386).

Num estudo mais recente sobre os desafios da educação brasileira, Schwartzman (2005, p. 30) destaca que o Brasil, diferentemente de outros países, não elaborou um sistema próprio para a formação do professor e aponta que a formação "ficou isolada e relegada aos segmentos de menor prestígio das instituições do ensino superior e à iniciativa privada, sem a elaboração de sólidos programas de pós-graduação e pesquisa, como os existentes para as ciências naturais e as sociais mais acadêmicas".

Como decorrência, constata-se a proliferação das diversas modalidades de cursos para formar os professores, o que, segundo Michels (2006, p. 414), "impele os professores das redes públicas, especificamente aqueles profissionais do ensino fundamental, a procurar sua formação em instituições que prometem formá-los em menos tempo, com menos gastos, entre outros pontos que caracterizam o aligeiramento da formação docente".

Corroborando a tese de Patinha (1999) em que questiona a formação em serviço indicada pelas políticas neoliberais a fim de reduzir custos, Michels (2006, p. 414) acrescenta que podemos chamar, hoje, no Brasil, a formação de professores como treinamento profissional, formação essa fornecida a professores leigos, que segundo a autora, ganham menos, não fazem exigências trabalhistas e são fáceis de descartar.

É nesse quadro que surgem os Programas Especiais de Formação de Professores criados em caráter provisório, mas que vêm crescendo e permanecendo como uma opção para as instituições privadas, dado seu reduzido custo e em razão da demanda de alunos apresentada.

\section{Os programas especiais de formação de professores: algumas repercussões}

Pouco tempo depois da promulgação da LDB n. ${ }^{\circ} 9.394 / 96$, já surgia um primeiro dispositivo impactante no campo da formação de professores: a Resolução CNE nº 2/97, da qual trata esta pesquisa.

Essa Resolução tinha por objetivo, conforme descrito em seu artigo primeiro, parágrafo único, "suprir a falta nas escolas de professores habilitados, em determinadas disciplinas e localidades, em caráter especial" e previa que os ingressantes desses programas fossem portadores de diploma de nível superior, em cursos afins à habilitação pretendida, com "sólida base de conhecimentos na área de estudos ligada a essa habilitação". Mais tarde, analisando a exigência quanto a esses "conhecimentos" prévios, percebemos que se tratava apenas da apresentação de histórico escolar, de nível superior, composto por disciplinas diretamente ligadas à habilitação e cujo tempo mínimo necessário era de 160 horas em toda a graduação.

Rev. Diálogo Educ., Curitiba, v. 8, n. 23, p. 105-120, jan./abr. 2008 
Cabe aqui um questionamento em relação aos sujeitos dessa pesquisa - professores de matemática que cursam tal Programa: com 160 horas de disciplinas relacionadas com a Matemática, é possível ter conhecimentos sólidos para a docência?

Outra observação é a de que a responsabilidade em verificar a compatibilidade entre o candidato ao Programa Especial e sua formação anterior com relação à habilitação pretendida foi delegada às instituições privadas que tivessem interesse em oferecer esses programas.

Em seus artigos $4^{\circ}$ e $5^{\circ}$, a Resolução $02 / 97$ prevê a necessidade de 300 horas de prática desenvolvidas em instituições de ensino básico, envolvendo "todas as atividades próprias da vida da escola, incluindo o planejamento pedagógico, administrativo e financeiro, as reuniões pedagógicas, os eventos com participação da comunidade escolar e a avaliação da aprendizagem, assim como de toda a realidade da escola". Contudo, a supervisão da parte prática é de responsabilidade da instituição que ministra o Programa Especial.

Para finalizar, em seu artigo $8^{\circ}$, a Resolução 02/97 permite que a parte teórica utilize metodologia semipresencial na modalidade de ensino a distância.

Na busca investigativa para entender como a LDB n. 9394/96 permitiu a criação de Programas Especiais de Formação Pedagógica, possibilitando a inserção de profissionais de áreas desvinculadas à educação, pode-se encontrar uma consideração de Linhares; Silva (2003, p. 44-45), que respondia aos questionamentos postos: ao prever o aproveitamento de "outras atividades", expressão extremamente vaga e ampla, a Lei propiciou que experiências de formação vividas em áreas desvinculadas do campo educacional pudessem ser aproveitadas no processo de formação de professores. Daí para a criação dos programas especiais foi um passo relativamente simples, tendo em vista a carência comprovada de professores em algumas áreas, notadamente no ensino das disciplinas da área de ciências matemáticas e naturais e de línguas estrangeiras.

Os autores acima levantam as hipóteses de que com a atual situação econômica do país, a busca por esses Programas Especiais funciona como estratégia de sobrevivência no mercado de trabalho, considerando-se a rapidez de sua duração, tornando-se uma ótima oportunidade de "empregabilidade" para profissionais de nível superior desempregados ou ameaçados de perder o emprego, ou mesmo como renda complementar, tendo em vista a má situação salarial, em geral.

Essas hipóteses serão respondidas ao final dessa pesquisa, apresentando dados conclusivos sobre o perfil desses profissionais e suas motivações para a investidura na área da educação, tendo como referência o estudo de um curso de uma determinada instituição.

Esses programas especiais foram criados para atender a uma necessidade emergencial e tinham caráter provisório, de modo que, conforme Linhares e Silva (2003, p. 46-47), eles não fossem percebidos como alternativas duradouras para resolver o problema da carência de professores.

Rev. Diálogo Educ., Curitiba, v. 8, n. 23, p. 105-120, jan./abr. 2008 
Tal idéia baseava-se justamente na constatação de que os programas são inócuos no combate ao problema do déficit de professores. Assim, paralelamente à adoção dos programas, as redes públicas e privadas de educação deveriam ser levadas, por força de uma determinação legal, que poderia ser a mesma resolução que regulamenta os programas especiais, a cumprir, num determinado prazo, uma agenda mínima em termos de valorização socioprofissional dos professores por elas empregados. Findo esse prazo, far-seia uma profunda avaliação da medida, de modo que se pudesse inclusive examinar a necessidade de continuar com os programas especiais.

No entanto, em função da necessidade de implantação de uma política educacional de resultados, os Programas Especiais, que foram implantados em 1997, com caráter provisório, foram corroborados em 1999 e, em 2001, é apresentado o parecer CNE/CP 025/2001. A partir daí, profissionais das demais áreas, desvinculados da educação passam a ingressar nesses programas em busca de uma formação que lhes permite uma nova profissão.

Dizemos isso, pois, no início, os profissionais que buscavam esse tipo de formação, segundo informações de professores que ministraram aulas nesses Programas, no início de sua implantação, eram os professores nãohabilitados que já atuavam como professores há muitos anos e que precisavam de uma certificação.

Assim, a proposta caracterizava o curso como uma formação continuada, a fim de certificar aqueles que de alguma forma já haviam buscado e obtido conhecimentos práticos e teóricos para o exercício de sua profissão. Porém, ao se institucionalizar esses Programas de forma definitiva, fornecendo um certificado de Licenciatura Plena, profissionais de diversas áreas partiram em busca de uma "alternativa profissional".

Os resultados dessa pesquisa nos alerta para a necessidade de se questionar o funcionamento de cursos de formação de professores nos moldes desse que é objeto do nosso estudo, tendo em vista que partem do pressuposto de que os conhecimentos "sólidos" sobre Matemática, por exemplo, foram adquiridos em cursos de nível superior que tivessem em sua grade curricular 160 horas de Matemática, sem qualquer tipo de relação com o ensino de Matemática ou aprofundamento de conteúdo.

Linhares (2001) apresenta o Programa Especial de Formação Pedagógica (Resolução 02/97) como sendo um dos rumos demarcados pelos reformadores a fim de "atender à demanda de setores da classe média e de profissionais liberais no sentido de fornecer-lhes oportunidades de ocupar postos de professores, atenuando os efeitos do desemprego, mediante uma complementação rápida" e Waldeck Carneiro da Silva (2001, p. 131-132) faz a relação com essa necessidade do mundo capitalista, globalizado, de "terceiro

Rev. Diálogo Educ., Curitiba, v. 8, n. 23, p. 105-120, jan./abr. 2008 
mundo", expondo que, sob pretexto de reduzir o déficit de professores - provocado principalmente pela evasão profissional e pelo refugo de professores formados em ingressar na carreira, diante das condições salariais por vezes degradantes -, o CNE aprovou em 1997 a Resolução n. 02/97, que oferece a profissionais titulados em nível superior a oportunidade de obter, após ligeiro processo de "preparação" (programa especial de formação), um certificado que os habilita a lecionar nas séries finais do ensino fundamental e no ensino médio.

Linhares e Silva (2003, p. 40) também retornam à análise do mercado, "focalizando agora a mercantilização voraz da oferta de cursos superiores de formação de professores também para a educação infantil e para os anos iniciais do ensino fundamental, com terríveis conseqüências para a qualidade dessa formação". Com isso afirmam:

O aproveitamento indiscriminado de experiências anteriores para justificar contabilmente a redução de carga horária, a ênfase em metodologias que dispensam a interação presencial e os cursos oferecidos nos finais de semana está entre as principais estratégias para ampliar o número de candidatos ao curso (clientes) e diminuir a duração dele, aumentando a rentabilidade do investimento (LINHARES; SILVA, 2003, p. 40).

Constata-se, assim, que as análises aqui trazidas tomam como pano de fundo o quadro político-econômico que vem definindo o processo de formação dos professores e, como alguns estudos indicam, vem corroendo o processo de profissionalização docente (APPLE, 1990; LOURENCETTT, 2004; CUNHA, 2005). Sabe-se que falar de formação e profissionalização de professores sem vincular a análise do contexto das políticas neoliberais, segundo Cunha (2005, p. 13), "pode ser uma forma de escamotear as verdadeiras emergências de reconstrução do trabalho do professor".

\section{Sujeitos investigados e instrumentos de pesquisa}

Para fins de apresentação dos sujeitos investigados importa destacar que o grupo de alunos pesquisados era formado por alunos interessados em obter o certificado de Licenciatura Plena em: Matemática, História ou Letras. Dentre as 6 (seis) disciplinas ministradas durante o ano letivo, apenas uma era relacionada à área específica de estudo; no caso, Metodologia do Ensino da Matemática. Assim, os grupos foram divididos em 3 (três) apenas durante as aulas de uma única disciplina (específica). Desta forma, todos os alunos matriculados nesta turma do PEFP cursavam as aulas ao mesmo tempo, numa única sala de aula. Porém, no segundo semestre, no período da tarde, esta turma era dividida em 3 subgrupos para que pudessem assistir a aulas diferentes de disciplinas específicas relacionadas a cada área, como, por exemplo, o grupo que

Rev. Diálogo Educ., Curitiba, v. 8, n. 23, p. 105-120, jan./abr. 2008 
Professores não habilitados e os programas especiais de formação de professores

buscava a licenciatura em Matemática e assistia às aulas de Metodologia do Ensino de Matemática. Esta pesquisa faz referência ao grupo específico que obteve a titulação de Licenciatura Plena em Matemática, apesar de inseridos num contexto com alunos de outros grupos da mesma turma. Essas e outras considerações serão retomadas mais adiante.

Decidimos aplicar um questionário aos alunos do PEFP e traçar um perfil desse aluno, além de entender qual a compreensão que eles tinham sobre o processo de formação que estavam vivenciando, bem como sobre as razões que os levaram a escolher esse programa.

\section{Perfil dos sujeitos}

Como complemento à contextualização do curso e para melhor identificarmos o público-alvo do PEFP analisado, é relevante apresentar o perfil dos sujeitos dessa pesquisa, alunos da turma do PEFP, da instituição escolhida.

Dentre os sujeitos pesquisados, $50 \%$ tinham entre 31 e 40 anos de idade, $25 \%$ tinham entre 41 e 50 anos de idade e o restante era dividido entre 2 alunos (12,5\%) com idade entre 25 e 30 anos, 1 aluno com menos de 25 anos e 1 aluno com mais de 50 anos de idade.

A maior parte dos sujeitos residia próximo à instituição, elemento que analisaremos posteriormente como um dos fatores de motivação para cursarem o PEFP. Contudo, um deles residida há cerca $400 \mathrm{~km}$ de distância da instituição e, pela inexistência deste tipo de curso em qualquer região do interior paulista, viajava, de ônibus, durante as madrugadas de sexta e sábado para ir e voltar, a fim de obter o título necessário para manutenção de seu emprego.

Esse aluno possuía mais de 50 anos de idade, trabalhava em três períodos diferentes em escolas públicas, atuando como professor e coordenador há mais de 20 anos. Necessitava do título de Licenciatura Plena em Matemática para preservar sua preferência na atribuição de aulas da Secretaria da Educação do Estado de São Paulo, bem como para poder, no ano seguinte, conforme confirmação posterior, estudar no curso de Complementação Pedagógica, realizado na mesma instituição, para Licenciados que desejassem obter um certificado que os permitisse atuar como coordenadores, habilitando-os, inclusive, para inscrição em concursos públicos.

A maioria dos alunos era casada, com filhos e $75 \%$ já havia lecionado antes, mesmo que por pouco tempo e boa parte deles lecionava no momento da pesquisa.

Quanto à formação inicial desses alunos, apenas 3 deles eram bacharéis em Matemática, 3 haviam estudado Processamento de Dados, 2 estudaram Engenharia, 1 aluno era graduado em Economia e Direito, $1 \mathrm{em}$ Arquitetura e 6 alunos (37,5\% da turma) eram graduados em Administração de

Rev. Diálogo Educ., Curitiba, v. 8, n. 23, p. 105-120, jan./abr. 2008 
Empresas. Deste modo, era possível perceber que 50\% desses sujeitos eram graduados em cursos de Humanas e estavam prestes a obter um título que os habilitaria lecionar Matemática por meio de um curso que não tinha em sua grade curricular disciplinas de Matemática.

Foram realizadas entrevistas semi-estruturadas e o foco de análise foi a compreensão das motivações que levaram essas pessoas a se matricularem no Programa Especial de Formação de Professores, suas motivações profissionais para o exercício da docência, bem como suas percepções sobre o PEFP e a profissão. Além disso, buscamos elementos que identificassem os conhecimentos adquiridos $\mathrm{e}$ as atividades e os aspectos que marcaram essas pessoas durante o PEFP.

A contextualização do Programa Especial pesquisado revela-se importante e revela que a instituição é uma das maiores instituições privadas do país e no período estudado (2005-2007) a formação ocorria em 3 Câmpus e, no momento presente, essa modalidade de formação é oferecida em todos os Câmpus da instituição.

Apenas no Câmpus onde o programa foi pesquisado, havia, além da turma analisada, mais 3 turmas, organizadas após o início das aulas, devido à demanda pelo Programa Especial. Cada turma era composta por cerca de 60 alunos, incluindo alunos que buscavam a Licenciatura Plena em Matemática, História ou Letras. Dentre os cerca de 60 alunos que compunham essa turma, aproximadamente 22 alunos buscavam a Licenciatura Plena em Matemática.

A análise de documentos também foi utilizada e foram privilegiados as grades curriculares do curso e os pareceres que dispõem sobre Programas Especiais de Formação de Professores: Parecer CNE/CP 02/97; o parecer 25/ 2001, que veio homologar o Parecer 02/97.

O curso era composto por 6 disciplinas, distribuídas de tal forma que em cada semestre eram ministradas 3 disciplinas, sendo 2 delas bimestrais e uma semestral. Fundamentos da Educação e Metodologia e Prática de Ensino de Matemática tinham duração de um semestre e Teorias da Aprendizagem, Proposta Pedagógica e Planejamento do Ensino e Avaliação da Aprendizagem constituíam as disciplinas bimestrais. Embora os programas das disciplinas sejam padronizados e disponíveis no site da instituição, cada professor o apresentava a sua maneira e sem sofrer o controle da instituição.

\section{Em forma de síntese: da busca pela certificação ao caminho de autodesvalorização}

Nos dados apontados pelos questionários em relação à motivação pela escolha do curso, encontramos mais de $80 \%$ das respostas como sendo a busca por uma certificação, ou simplesmente, o "papel", como muitos "disseram".

Rev. Diálogo Educ., Curitiba, v. 8, n. 23, p. 105-120, jan./abr. 2008 
Professores não habilitados e os programas especiais de formação de professores

Dentre esses, alguns ainda citaram o fato de ser um curso rápido. Os demais responderam que a razão dessa escolha foi a oportunidade de uma alternativa profissional caso fiquem desempregados. Esse parece ser um ponto que contradiz a concepção do significado de um processo de formação docente baseado na vivência e na busca por uma formação de qualidade, que prepare o professor para ser o profissional do ensino, exercendo sua profissão com base no conceito da profissionalidade, ou seja, com um conjunto de características essenciais, conhecimentos, destrezas, atitudes e valores específicos de uma dada profissão, segundo Gimeno (1991) e Flores (2003).

Parece evidente que a busca pelo PEFP tem motivações diversas, mas nenhuma parece ser a necessidade ou a busca por conhecimentos e/ou por atualizações na área.

A segunda entrevistada, ao ser questionada sobre sua procura pelo PEFP, responde: "porque era mais rápido, mais fácil, mais barato, mais próximo da minha casa e como eu já estava dando aula de Matemática sem ter o diploma, eu precisava do diploma o mais rápido possível...então...foi por isso que eu fiz esse".

Mais uma vez o tempo está presente como um forte motivador na busca pelo PEFP, bem como a exigência legal pela titulação.

Analisando os dados apresentados acima, parece-nos que o primeiro ponto a questionar diz respeito aos objetivos dos alunos ao buscarem o Programa e a relação com a qualificação para o exercício profissional que esta formação propicia.

Nesse aspecto, surge a pergunta: Como envolver esses alunos para que desenvolvam uma postura mais profissional, valorizando a formação do professor e a busca incessante por conhecimentos que os prepare e os mantenha atualizados para o exercício dessa profissão? Como proporcionar uma formação de qualidade ao se deparar com atitudes contrárias a este objetivo?

Além desse elemento, encontramos, também, algumas respostas que indicaram o redescobrir de alguns alunos para o conhecimento e para o estudo.

No entanto, as respostas indicaram que a busca pelo conhecimento estava atrelada mais às disciplinas que responderiam às situações práticas de sala de aula. Alguns alunos apontaram os conhecimentos teóricos adquiridos na disciplina Teorias da Aprendizagem, vivenciando a oportunidade de conhecerem as teorias de Piaget, Vygotsky e Wallon, sobre as quais nunca haviam lido ou ouvido qualquer comentário, mesmo aqueles sujeitos que já lecionavam há mais de 20 anos. Por outro lado, há que se considerar que com o número de encontros realizados, pode-se inferir que muito pouco dessas teorias pode ser explorado.

Outros indicaram as atividades com jogos matemáticos e que são diretamente voltadas para a resolução dos problemas da prática cotidiana.

Outro foco de análise são os conhecimentos adquiridos no PEFP e os aspectos que marcaram o programa, segundo os sujeitos de pesquisa.

Rev. Diálogo Educ., Curitiba, v. 8, n. 23, p. 105-120, jan./abr. 2008 
Vimos, em várias respostas dos alunos, que muitos revelaram uma mudança no discurso a respeito da motivação pela busca de novos conhecimentos, ou seja, o que antes era apenas "ter o papel” para poder lecionar ou "exigência legal", agora é destacado por Amanda como: "comecei a enxergar o aluno e suas necessidades e a educação de uma forma mais completa", ou ainda, "incentivaramme a investigar sobre outros conhecimentos; repensar formas de avaliar e perceber se houve aprendizagem por parte do aluno; repensar postura de professor, motivação e outros aspectos que facilitem a educação efetiva". Percebemos, também, o despertar para temas antes desconhecidos, como na frase de Maria: "Alguns textos me trouxeram curiosidades em pesquisar mais sobre o assunto, como no caso da etnomatemática".

Outro dado interessante é a resposta da professora Laura, que lecionava há 13 anos em cursos técnicos, ao revelar que não conhecia os PCNs. Esses dados revelam o desconhecimento dos professores dos conhecimentos básicos para sua atuação profissional e que demandam um tempo maior para o estudo, para o debate, a troca e a reflexão.

Por outro lado, a troca de experiências com outros profissionais que já lecionam foi apontada como ponto-chave dos encontros aos sábados.

Em relação à percepção dos alunos sobre seus professores do Programa, trazemos a fala de uma delas ao dizer que utilizou "a postura e as estratégias adotadas pela maioria dos professores do Programa Especial como um grande exemplo para não cometer os mesmos erros". Neste ponto, a entrevistada esclarece que os professores deveriam "usar melhor o tempo e diversificar mais as estratégias". Observa-se, aqui, que a percepção de algo ruim foi utilizada como referência para não ser repetida.

Um dado destacado pelos sujeitos e é revelador das condições desses professores para o exercício da atividade docente é a necessidade por eles indicada sobre o conhecimento matemático específico. Para um dos sujeitos, “[...] o ambiente de troca me faz gostar das aulas, mas o curso está me preparando apenas em poucos momentos e não tem o que considero fundamental: domínio de conteúdos. Noventa por cento de minha sala não sabe os conteúdos de matemática e ao fim do ano estarão habilitados para dar aula. Que professor ele será?”

Tomados aqui alguns dos elementos que marcaram o processo formativo vivido por esses professores e retomando a indignação das autoras no início do texto, pode-se argumentar que, mesmo com a escassez de professores tão anunciada nos últimos tempos, as políticas públicas têm contribuído para a precarização da formação dos professores e para o sentimento, tão generalizado de autodesvalorização profissional.

Rev. Diálogo Educ., Curitiba, v. 8, n. 23, p. 105-120, jan./abr. 2008 


\section{REFERÊNCIAS}

APPLE, M. Trabajo, ensenanza y discriminación sexual In: POPKEWITZ, T. (Org.). Formación del professorado: tradición, teoria y práctica. Valência: Universidade de Valência, 1990. p. 55-78.

ARANHA, WELLINGTON L. A. Professores eventuais nas escolas estaduais paulista: ajudantes de serviço geral da educação. Araraquara: Unesp, 2007. (Mimeo).

BRASIL. Presidência da República. Lei 9394/96, de 20/12/1996. Estabelece as diretrizes e bases da educação nacional. Diário Oficial da União, Brasília, ano 134, n. 248, p. 27833-41, dez. 1996,

CONSELHO NACIONAL DE EDUCAÇÃO. Resolução CNE/CP $\mathbf{n}^{\circ} 2$, de 26 de junho de 1997. Que dispõe sobre os Programas Especiais de Formação Pedagógica de Docente para as disciplinas do currículo do Ensino Fundamental e do Ensino Médio e da educação profissional em Nível Médio. Relator: Silke Weber. Brasília: CNE, 1997.

CONSELHO NACIONAL DE EDUCAÇÃO Parecer CNE/CP $\mathbf{n}^{\mathbf{0}}$ 25 de 02 de outubro de 2001. Que dispõe sobre os Programas Especiais de Formação Pedagógica de Docente para as disciplinas do currículo do Ensino Fundamental e do Ensino Médio e da Educação Profissional em Nível Médio. Relator Silke Weber: CNE, 2001.

CANDAU, Vera Maria Ferrão (Coord.). Novos rumos da licenciatura. Brasília: INEP, 1989.

CUNHA, M. I. Formatos avaliativos e concepção de docência. Campinas: Autores Associados, 2005.

DIAS-DA-SILVA, M. H. F. Políticas de formação de professores no Brasil: as ciladas da reestruturação das licenciaturas Perspectiva, Florianópolis, v. 23, n. 2, p. 381-406, jun/dez 2005.

FLORES, M. A. Dilemas e desafios na formação de professores. In: MORAES, M. C.; PACHECO, J. A.; EVANGELISTA, M. O. (Org.). Formação de professores: perspectivas educacionais e curriculares. Porto: Porto, 2003. cap. 7, p. 127-160.

FREITAS, H. C. L. A (nova) política de Formação de Professores: a Prioridade Postergada. Educação \& Sociedade, Campinas, v. 28, n. 100, p.1203-1230, Especial -out. 2007.

Rev. Diálogo Educ., Curitiba, v. 8, n. 23, p. 105-120, jan./abr. 2008 
GIMENO, J. Consciência e acção sobre a prática como libertação profissional dos professores. In: NÓVOA, A. (Org.). Profissão professor. Porto: Porto, 1991. p. 93-124.

LINHARES, C. Professores entre reformas escolares e reinvenções educativas. In: LINHARES, C. (Org.). Os professores e a reinvenção da escola: Brasil e Espanha. São Paulo: Cortez, 2001. p. 137-174.

LINHARES, C.; SILVA, W. C. Formação de professores: travessia crítica de um labirinto legal. Brasília: Plano, 2003.

LOURENCETTI, G. C. Mudanças sociais e reformas educacionais: repercussões no trabalho docente. 2004. 158 f. Tese (Doutorado em Educação Escolar) - Universidade Estadual de São Paulo, Araraquara, 2004.

LÜDKE, M. Avaliação institucional: formação de docentes para o ensino fundamental e médio (As Licenciaturas). Estudos e Debates, Brasília, n. 19, p. 137-196, maio. 1997.

MAUÉS, O. C. Reformas internacionais da educação e formação de professores. Cadernos de Pesquisa, São Paulo, n. 118, p. 89-117, mar. 2003.

MICHELS, M. H. Gestão, formação docente e inclusão: eixos da reforma educacional brasileira que atribuem contornos à organização escolar. Revista Brasileira de Educação, Rio de Janeiro, v. 11, n. 33, p. 406-423, set./dez. 2006

PATINHA, V. A. Professor não-habilitado: um sinal da crise na educação. 1999. 212 f. Tese (Doutorado em Educação: História e Filosofia da Educação) - Pontifícia Universidade Católica de São Paulo, São Paulo, 1999.

SCHWARTZMAN, S. Os desafios da educação no Brasil. Rio de Janeiro, Nova Fronteira, 2005.

SILVA, Waldeck Carneiro da. Universidade e sociedade no Brasil. Rio de Janeiro: Quartet, 2001.

WARDE, M. J. Algumas reflexões sobre Licenciaturas e Pedagogia. Ciência e Cultura, São Paulo, v. 20, p. 1262-1264, 1985.

Recebido: 06/10/2007

Received: $10 / 06 / 2007$

Aprovado: 05/11/2007

Approved: $11 / 05 / 2007$

Rev. Diálogo Educ., Curitiba, v. 8, n. 23, p. 105-120, jan./abr. 2008 